\title{
Mechanical and Tribological Properties of PVD-Coated Cemented Carbide as Evaluated by a New Multipass Scratch-Testing Method
}

\author{
M. Fallqvist, ${ }^{1}$ R. M'Saoubi, ${ }^{2}$ J. M. Andersson, ${ }^{2}$ and M. Olsson ${ }^{1}$ \\ ${ }^{1}$ Department of Material Science, Dalarna University, 78188 Borlänge, Sweden \\ ${ }^{2}$ R\&D Materials and Processes, Seco Tools AB, 73782 Fagersta, Sweden \\ Correspondence should be addressed to M. Fallqvist,mfa@du.se
}

Received 22 March 2012; Accepted 12 October 2012

Academic Editor: Shyam Bahadur

Copyright ( $) 2012$ M. Fallqvist et al. This is an open access article distributed under the Creative Commons Attribution License, which permits unrestricted use, distribution, and reproduction in any medium, provided the original work is properly cited.

\begin{abstract}
A new test method based on multipass scratch testing has been developed for evaluating the mechanical and tribological properties of thin, hard coatings. The proposed test method uses a pin-on-disc tribometer and during testing a Rockwell C diamond stylus is used as the "pin" and loaded against the rotating coated sample. The influence of normal load on the number of cycles to coating damage is investigated and the resulting coating damage mechanisms are evaluated by posttest scanning electron microscopy. The present study presents the test method by evaluating the performance of $\mathrm{Ti}_{0.86} \mathrm{Si}_{0.14} \mathrm{~N}, \mathrm{Ti}_{0.34} \mathrm{Al}_{0.66} \mathrm{~N}$, and $\left(\mathrm{Al}_{0.7} \mathrm{Cr}_{0.3}\right)_{2} \mathrm{O}_{3}$ coatings deposited by cathodic arc evaporation on cemented carbide inserts. The results show that the test method is quick, simple, and reproducible and can preferably be used to obtain relevant data concerning the fatigue, wear, chipping, and spalling characteristics of different coating-substrate composites. The test method can be used as a virtually nondestructive test and, for example, be used to evaluate the fatigue and wear resistance as well as the cohesive and adhesive interfacial strength of coated cemented carbide inserts prior to cutting tests.
\end{abstract}

\section{Introduction}

Although CVD (chemical vapour deposition) and PVD (physical vapour deposition) coatings have been used in order to increase the lifetime and performance of cutting tools for more than 30 years there is still an intensive research interest to improve the performance of existing coating materials and to develop new coating materials and coating processes. Even though many test methods have been developed to simulate the contact conditions prevailing during metal cutting conditions, cutting tests are still the most reliable methods in order to characterize the properties and performance of coatings-substrate systems aimed for metal cutting operations $[1,2]$. However, cutting tests including in-depth post-test characterization of the worn cutting tools can be both costly and time-consuming. Consequently, laboratory tests, although performed at room temperature, can preferably be used in order to evaluate specific properties such as the cohesive and adhesive strength, intrinsic abrasion resistance, and so forth of specific coating systems. As a result, a wide range of laboratory techniques are available to assess the mechanical and tribological characteristics of CVD and PVD coatings for metal cutting tools [3-13].

Today, the scratch test is probably the most common and used test to increase the understanding of the mechanical response of a coating-substrate system exposed to an external load [12]. In the conventional scratch test a Rockwell C diamond stylus $\left(120^{\circ}\right.$ cone with $200 \mu \mathrm{m}$ radius) is drawn across the coated substrate surface under an increasing normal load until some kind of well-defined coating failure occurs, frequently associated with localized chipping or spalling [3]. The corresponding normal load is termed the critical load and is often used as a measure of the coating mechanical strength or "practical adhesion." The critical load can be detected by on-line monitoring of the friction force and acoustic emission signals and/or by post-test examination using optical or scanning electron microscopy [12-18].

One drawback with the conventional scratch test is the need for such high normal loads that the deformation behaviour of the substrate material in many cases controls the mechanical response of the coating-substrate system, 
TABle 1: Deposition process parameters and thickness for the coatings investigated.

\begin{tabular}{lccc}
\hline & $\mathrm{Ti}_{0.86} \mathrm{Si}_{0.14} \mathrm{~N}$ & $\mathrm{Ti}_{0.34} \mathrm{Al}_{0.66} \mathrm{~N}$ & $\left(\mathrm{Al}_{0.7} \mathrm{Cr}_{0.3}\right)_{2} \mathrm{O}_{3}$ \\
\hline Thickness $(\mu \mathrm{m})$ & 2.5 & 2.5 & 3.5 \\
Cathode & $\mathrm{Ti}_{0.80} \mathrm{Si}_{0.20}$ & $\mathrm{Ti}_{0.33} \mathrm{Al}_{0.67}$ & $\mathrm{Al}_{0.70} \mathrm{Cr}_{0.30}$ \\
Atmosphere & $\mathrm{N}_{2}$ & $\mathrm{~N}_{2}$ & $\mathrm{O}_{2}$ \\
Pressure $(\mathrm{Pa})$ & 4 & 4 & 1 \\
Bias $(\mathrm{V})$ & -30 & -50 & -100 \\
Temp. $\left({ }^{\circ} \mathrm{C}\right)$ & 450 & 450 & 550 \\
\hline
\end{tabular}

TABLE 2: Characteristic properties of the investigated coatings in the as-deposited condition.

\begin{tabular}{lccc}
\hline & $\mathrm{Ti}_{0.86} \mathrm{Si}_{0.14} \mathrm{~N}$ & $\mathrm{Ti}_{0.34} \mathrm{Al}_{0.66} \mathrm{~N}$ & $\left(\mathrm{Al}_{0.7} \mathrm{Cr}_{0.3}\right)_{2} \mathrm{O}_{3}$ \\
\hline$R_{a}(\mathrm{~nm})$ & $87 \pm 7$ & $77 \pm 5$ & $174 \pm 10$ \\
$R_{z}(\mu \mathrm{m})$ & $5.1 \pm 0.5$ & $5.1 \pm 0.9$ & $7.2 \pm 1$ \\
Droplets $\left(\mathrm{no} / 100 \mu \mathrm{m}^{2}\right)$ & $6.3 \pm 0.9$ & $4.9 \pm 0.7$ & $14.3 \pm 2$ \\
Area ratio droplets $(\%)$ & $4.6 \pm 0.8$ & $2.7 \pm 0.6$ & $18.8 \pm 4$ \\
Craters $\left(\right.$ no/ $\left.100 \mu \mathrm{m}^{2}\right)$ & $0.4 \pm 0.05$ & $0.4 \pm 0.06$ & $0.1 \pm 0.02$ \\
$\begin{array}{l}\text { Area ratio craters }(\%) \\
\text { Hardness, composite }\end{array}$ & $0.7 \pm 0.2$ & $0.8 \pm 0.2$ & $0.3 \pm 0.1$ \\
$(\mathrm{GPa})$ & $22 \pm 1.5$ & $20 \pm 1$ & $19 \pm 2$ \\
$\begin{array}{l}E \text {-modulus composite } \\
(\mathrm{GPa})\end{array}$ & $420 \pm 30$ & $500 \pm 40$ & $380 \pm 36$ \\
$\begin{array}{l}\text { Hardness, coating } \\
(\mathrm{GPa})\end{array}$ & $38 \pm 4$ & $30 \pm 3$ & $24 \pm 2$ \\
$\begin{array}{l}E \text {-modulus coating } \\
(\mathrm{GPa})\end{array}$ & $500 \pm 70$ & $570 \pm 80$ & $440 \pm 60$ \\
$\begin{array}{l}H_{\text {coat }} / E_{\text {coat }} \\
\text { Thickness }(\mu \mathrm{m})\end{array}$ & 0.08 & 0.05 & 0.06 \\
\hline
\end{tabular}

*The $H / E$ ratio is $0.04(17.1 / 426)$ for the cemented carbide.

including the adhesion of the coating to the underlying substrate. This is to a large extent due to the fact that the coating deposition processes including substrate cleaning and pre-treatment of today result in excellent adhesion.

An alternative test, able to evaluate the mechanical properties including the fatigue resistance of CVD and PVD coatings is the repetitive impact test $[5,19-21]$. In this test the coated substrate is exposed to an oscillating indenter, usually a ceramic or a cemented carbide ball, impacting the surface at a constant maximum force during a large number of impacts, typically $10^{6}$. The major drawbacks with this test are the large contact area and the fact that compressive stresses dominates while in a typical tribological contact coating failure is mainly due to the presence of tensile stresses $[19,20]$.

Consequently, a more realistic testing approach would be a test based on multi-pass scratch testing performed at lower loads, that is, loads significantly lower than the critical normal loads obtained in the conventional scratch test. In the multi-pass scratch test, a constant normal load lower than the critical load, is applied to the same scratch track for a large number of repeated cycles [22-27].
TABLE 3: Critical normal loads of the coatings investigated for Rockwell C diamond styli with radius $50 \mu \mathrm{m}$ and $200 \mu \mathrm{m}$, respectively.

\begin{tabular}{lccc}
\hline & $\mathrm{Ti}_{0.86} \mathrm{Si}_{0.14} \mathrm{~N}$ & $\mathrm{Ti}_{0.34} \mathrm{Al}_{0.66} \mathrm{~N}$ & $\left(\mathrm{Al}_{0.7} \mathrm{Cr}_{0.3}\right)_{2} \mathrm{O}_{3}$ \\
\hline$F_{\mathrm{N}, \mathrm{C} 1}, R=50 \mu \mathrm{m}[\mathrm{N}]$ & $19 \pm 1$ & $23 \pm 1$ & $17 \pm 1$ \\
$F_{\mathrm{N}, \mathrm{C} 2}, R=50 \mu \mathrm{m} \mathrm{[N]}$ & $22 \pm 1$ & $25 \pm 1$ & $20 \pm 1$ \\
$F_{\mathrm{N}, \mathrm{c} 1}, R=200 \mu \mathrm{m}$ & $60 \pm 1$ & $68 \pm 1$ & $51 \pm 1$ \\
{$[\mathrm{~N}]$} & & & \\
$F_{\mathrm{N}, \mathrm{C} 2}, R=200 \mu \mathrm{m}$ & $66 \pm 2$ & $74 \pm 2$ & $55 \pm 3$ \\
{$[\mathrm{~N}]$} & &
\end{tabular}

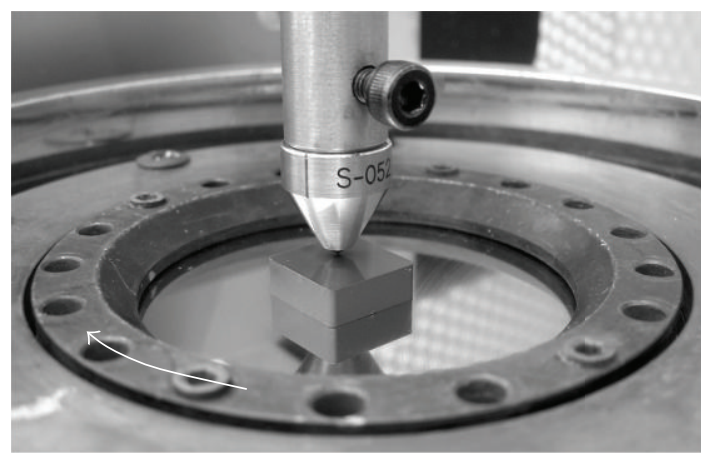

Figure 1: Instrumental test set-up used in the present study. The arrow indicates the rotating direction.

The objectives of the present study are to:

(a) propose a new test concept for multi-pass scratch testing using a pin-on-disc tribometer;

(b) evaluate the new test concept by studying the multipass fatigue andwear properties of three different PVD coatings used for metal cutting applications.

The new test approach is based on a three-step procedure aimed at evaluating the mechanical and tribological properties of CVD and PVD coatings under repeated scratching contact conditions. In the first step, conventional single pass scratch testing using a scratch tester is carried out to determine the critical normal load(s) for coating failure. In the second step, the data obtained from the conventional scratch test are used to perform multi-pass scratch testing at several sub-critical normal loads using a pin-on-disc tribometer. Finally, post-test examination of the tested samples is performed using scanning electron microscopy and energy dispersive X-ray spectroscopy in order to determine the major coating failure mechanisms.

\section{Experimental}

2.1. Materials. Commercial cemented carbide inserts with a composition of $94 \mathrm{wt} \% \mathrm{WC}$ and $6 \mathrm{wt} \%$ Co and hardness $1700 \mathrm{HV}_{0.020}$ were used as substrate material in the present study. Prior to coating deposition the substrate surfaces were polished to a surface finish of $R_{a} \approx 100 \mathrm{~nm}$. Three different PVD coatings, $\mathrm{Ti}_{0.86} \mathrm{Si}_{0.14} \mathrm{~N}, \mathrm{Ti}_{0.34} \mathrm{Al}_{0.66} \mathrm{~N}$ and 
TABLE 4: Schematic illustrations summarizing the observed coating damage mechanisms during the circular multi-pass scratch testing.

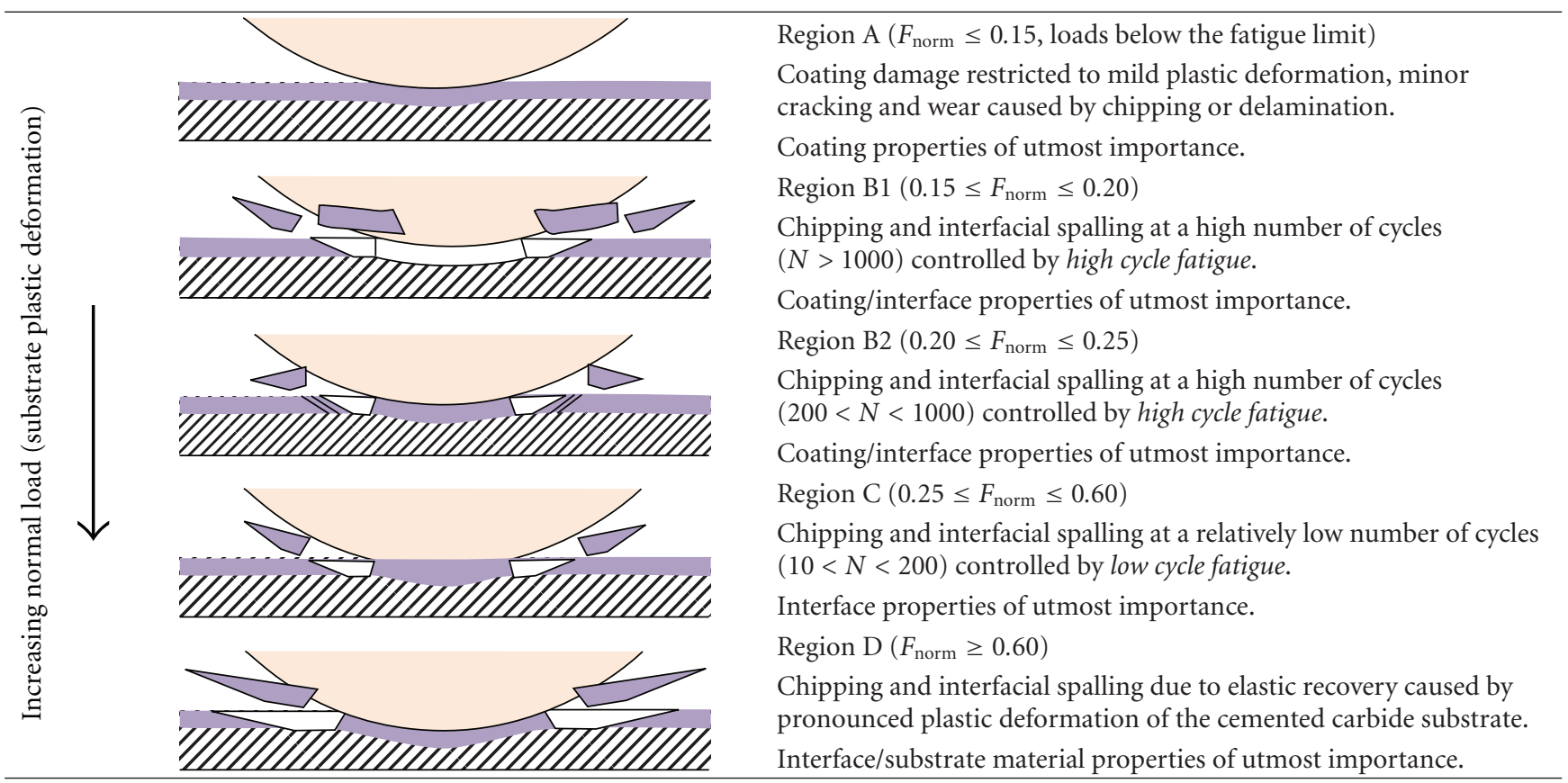

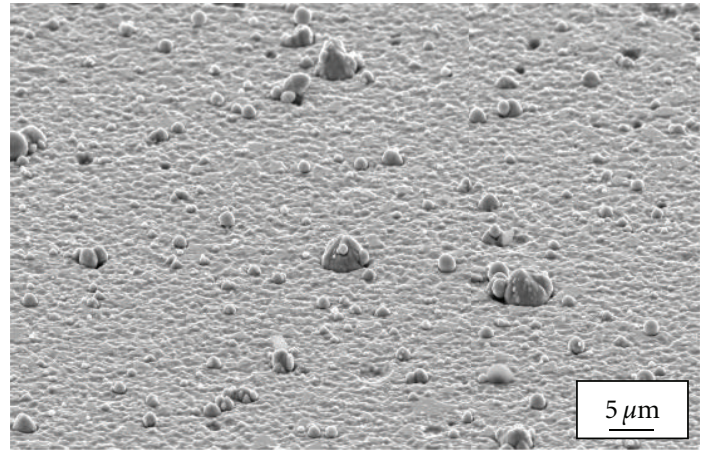

(a)

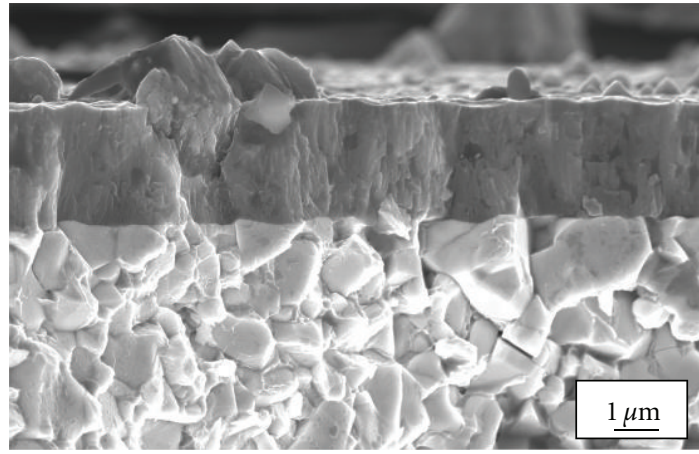

(b)

FIgURE 2: Surface morphology (a) and fractured cross-section (b) of $\mathrm{Ti}_{0.34} \mathrm{Al}_{0.66} \mathrm{~N}$ coating.

$\left(\mathrm{Al}_{0.7} \mathrm{Cr}_{0.3}\right)_{2} \mathrm{O}_{3}$, representing state of the art PVD coatings for metal cutting applications were included in the study. The coatings were deposited using cathodic arc evaporation with a coating growth rate of approximately $2 \mu \mathrm{m} / \mathrm{h}$ using the deposition process parameters according to Table 1 . When depositing the $\mathrm{Ti}_{0.86} \mathrm{Si}_{0.14} \mathrm{~N}$ and $\left(\mathrm{Al}_{0.7} \mathrm{Cr}_{0.3}\right)_{2} \mathrm{O}_{3}$ coatings a thin $\mathrm{Ti}_{0.34} \mathrm{Al}_{0.66} \mathrm{~N}$, layer (thickness $0.5 \mu \mathrm{m}$ ) was deposited in order to promote the adhesion to the underlying substrate. It should be noted that the chemical composition of the coatings has been determined by combining results from energy dispersive X-ray spectroscopy (EDX), Rutherford backscattering spectrometry (RBS) and elastic recoil detection analysis (ERDA).

2.2. Coating Characterization. The surface morphology, microstructure, and element composition of the as-deposited coatings were investigated using a $3 \mathrm{D}$ optical surface profilometer (WYKO NT-9100) and a ZEISS Ultra 55 field emission Gun Scanning Electron Microscope (FEG-SEM) equipped with an Oxford INCA Energy Dispersive XRay spectroscopy (EDX) system. The presence of defects (surface irregulaties), that is, droplets and craters in the asdeposited coating surfaces was evaluated using stereological methods (disector counting rule and point grid method) [28]. Only defects larger than $0.4 \mu \mathrm{m}$ were considered in five representative areas $(30 \times 50 \mu \mathrm{m})$ in the centre of each sample.

2.3. Mechanical Testing. The Vickers hardness values of the coatings and the coating-substrate composites were measured using a Micro Combi Tester (CSM Instruments), using a load of $200 \mathrm{mN}$ and $4000 \mathrm{mN}$, respectively. The indents using the lower load were all done in flat areas free from visible defects, resulting in hardness values for the defect free coating material. Loading and unloading were 


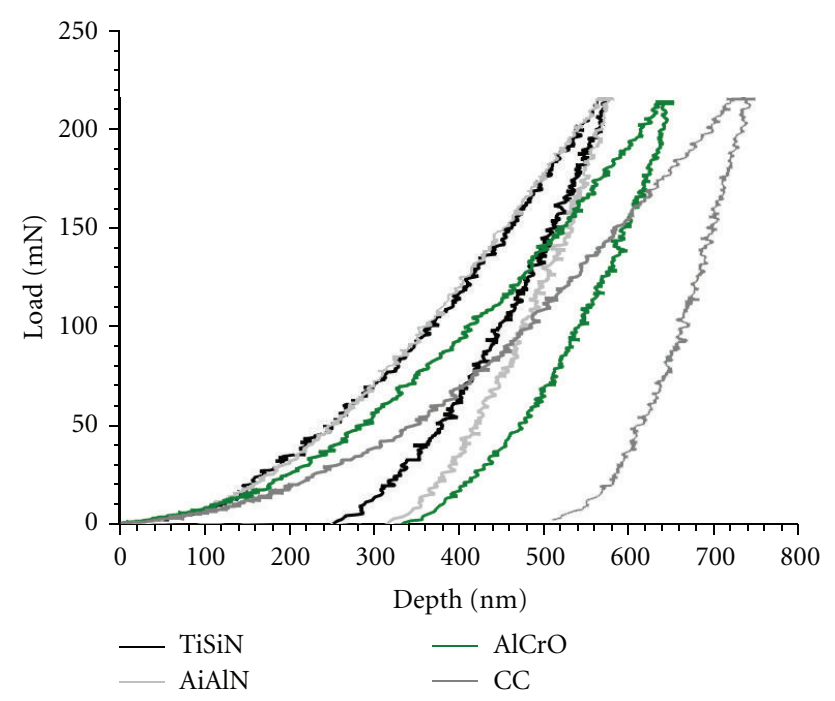

FIgURE 3: Indentation load-displacement curves obtained for the uncoated and the PVD coated cemented carbide substrates investigated.

performed for $30 \mathrm{~s}$, respectively, with a holding period of $15 \mathrm{~s}$ at the maximum load. By using the obtained indentation curves (load versus displacement) the hardness and Young's modulus were calculated according to Oliver-Pharr [29].

The Micro Combi Tester was also used in order to evaluate the resistance to scratch induced failure of the coatings. Single pass scratch testing under increasing normal load $(0-30 \mathrm{~N})$ with a scratch length of $10 \mathrm{~mm}$ and a scratching velocity of $10 \mathrm{~mm} / \mathrm{min}$ was performed using a $50 \mu \mathrm{m}$ radius Rockwell C diamond stylus. Besides, conventional single pass scratch testing, using the CSM Instruments Revetest, was performed using a $200 \mu \mathrm{m}$ radius Rockwell C diamond stylus. A normal load range of $0-100 \mathrm{~N}$, a scratch length of $10 \mathrm{~mm}$ and a scratching velocity of $10 \mathrm{~mm} / \mathrm{min}$ were used in the experiments. During scratch testing the friction force and acoustic emission (A.E.) signals were continuously recorded.

In the scratch tests, two critical normal loads $\left(F_{N, C 1}\right.$ and $F_{N, C 2}$, resp.) were used as a measure of the coating cohesive and interfacial adhesive strength and were taken as the normal load corresponding to the first local coating failure $\left(F_{N, C 1}\right)$ and continuous substrate exposure $\left(F_{N, C 2}\right)$ as determined by post-test characterization using SEM.

2.4. Tribological Testing. Circular multi-pass scratch testing was performed in order to evaluate the fatigue and wear behaviour of the coatings under repeated scratching contact conditions. The experiments were performed using a pin-ondisc test equipment (CSM High Temperature Tribometer), see Figure 1, but instead of a pin or a ball commonly used in standard sliding wear tests a Rockwell C diamond stylus used in conventional scratch testing (using a scratch tester) was used. The pin-on-disc test set-up makes it possible to significantly reduce the extensive time associated with multi pass scratch testing for a large number of cycles $(>10)$ using conventional scratch testing equipment.
The circular multi-pass tests were carried out using a $50 \mu \mathrm{m}$ radius Rockwell C diamond stylus, a speed of $90 \mathrm{~mm} / \mathrm{min}$ and with a stepwise (loading step $2 \mathrm{~N}$ ) increasing normal load from $3 \mathrm{~N}$ up to the critical normal load, $F_{N, C 2}$, as obtained from the conventional single pass scratch tests. The maximum number of cycles was set to 2000. The radius of the circular scratch track was $1.5,2.0$, or $2.5 \mathrm{~mm}$. It should be noted that as long as the diamond stylus used in the experiment is not damaged no influence from a variation in circular scratch track radius on coating failure tendency could be detected within the radius range and test parameters used.

All tests were performed in ambient air $\left(20-22^{\circ} \mathrm{C}, 25\right.$ $26 \% \mathrm{RH}$ ) and repeated two times. During testing the friction coefficient was continuously recorded and, in combination with post-test characterisation of the wear track using optical microscopy, used in order to determine the number of cycles to coating failure. After testing all wear tracks were carefully characterized by SEM and EDX in order to evaluate the influence of normal load and number of scratching cycles on the prevailing coating failure mechanisms.

\section{Results}

3.1. Coating Morphology and Microstructure. Figures 2(a) and 2(b) show the surface morphology and microstructure of the as-deposited $\mathrm{Ti}_{0.34} \mathrm{Al}_{0.66} \mathrm{~N}$ coating investigated. As can be seen, the as-deposited coating surface shows a significant roughness due to the generation of $\mu \mathrm{m}$ - and sub- $\mu \mathrm{m}$-sized droplets during the deposition process. Of these, the larger droplets $(>3-5 \mu \mathrm{m}$ in diameter) typically show an interdroplet distance in the range of $\sim 15-25 \mu \mathrm{m}$, that is, they constitute a nonnegligible area fraction of the coating. Also, $\mu \mathrm{m}$ and sub- $\mu \mathrm{m}$-sized craters contribute to the observed roughness. EDX-analysis of the droplets shows that these display a higher metal content, especially in the core, as compared with the surrounding coating matrix. The above observations are common for all coatings investigated. However, when comparing the three coatings, see Table 2, it is observed that the $\left(\mathrm{Al}_{0.7} \mathrm{Cr}_{0.3}\right)_{2} \mathrm{O}_{3}$ coating shows a significantly rougher surface as compared with the $\mathrm{Ti}_{0.86} \mathrm{Si}_{0.14} \mathrm{~N}$ and $\mathrm{Ti}_{0.34} \mathrm{Al}_{0.66} \mathrm{~N}$ coatings. The reason for this is mainly due to a large number of large, up to $5-6 \mu \mathrm{m}$ in diameter, droplets as compared to the other two coatings. The surface roughness and defect density are about the same for the $\mathrm{Ti}_{0.86} \mathrm{Si}_{0.14} \mathrm{~N}$ and $\mathrm{Ti}_{0.34} \mathrm{Al}_{0.66} \mathrm{~N}$ coatings, with slightly higher values for the $\mathrm{Ti}_{0.86} \mathrm{Si}_{0.14} \mathrm{~N}$ coating.

\subsection{Mechanical Properties}

3.2.1. Hardness. Figure 3 shows representative load-displacement curves for the coatings. From these curves, the corresponding Young's modulus, $E$, and hardness values can be calculated, see Table 2 . As can be seen, the $\mathrm{Ti}_{0.86} \mathrm{Si}_{0.14} \mathrm{~N}$ coating displays the highest hardness while the $\left(\mathrm{Al}_{0.7} \mathrm{Cr}_{0.3}\right)_{2} \mathrm{O}_{3}$ coating displays the lowest hardness. The $\left(\mathrm{Al}_{0.7} \mathrm{Cr}_{0.3}\right)_{2} \mathrm{O}_{3}$ coating also displays the lowest $E$-modulus while the $\mathrm{Ti}_{0.34} \mathrm{Al}_{0.66} \mathrm{~N}$ coating displays the highest $E$-modulus. 


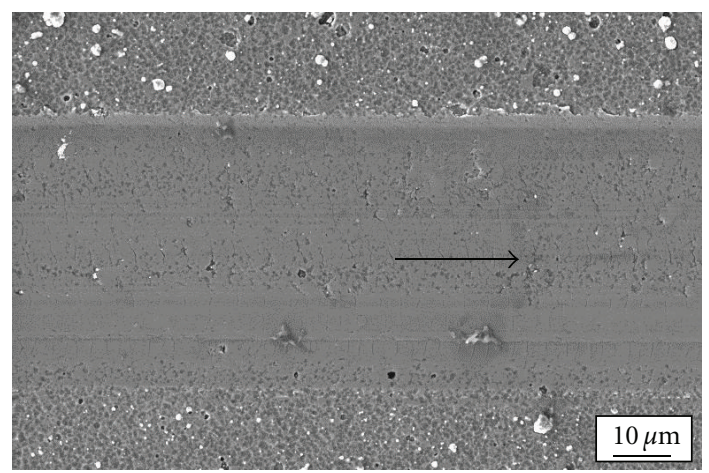

(a)

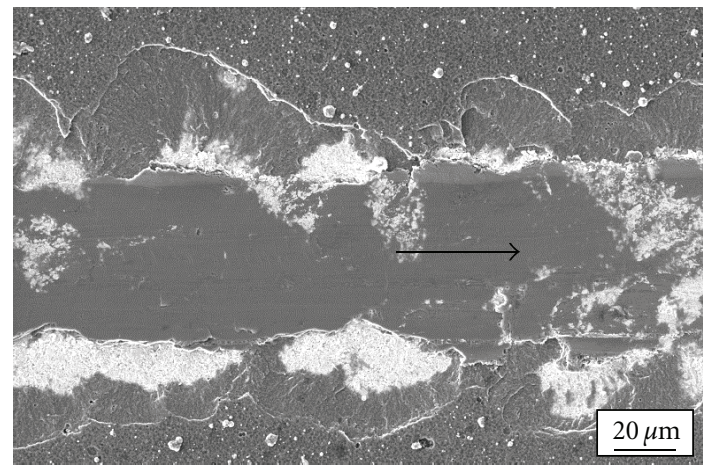

(c)

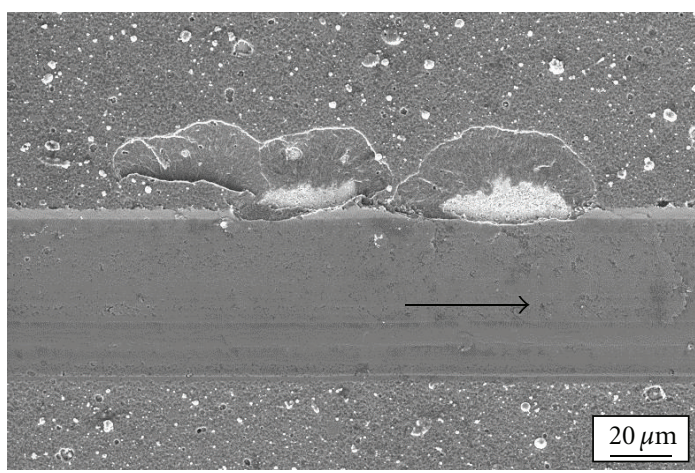

(b)

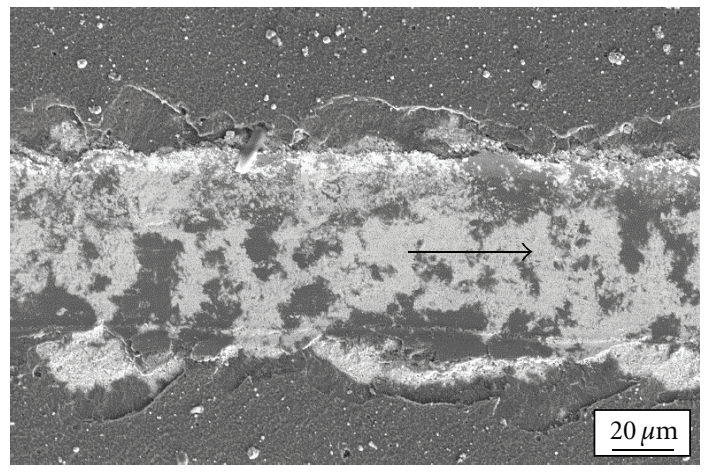

(d)

FIGURE 4: SEM micrographs illustrating the major coating failure mechanisms in the single-pass scratch test by using a diamond stylus with radius $R=50 \mu \mathrm{m}$. (a) Plastic deformation and minor cracking (no coating material detached), (b) chipping (cohesive failure) in combination with local interfacial spalling (adhesive failure), (c) continuous interfacial spalling (adhesive failure), and (d) continuous interfacial spalling in combination with extensive coating fragmentation at normal loads above $F_{N, C 2}$ for $\operatorname{Ti}_{0.34} \mathrm{Al}_{0.66} \mathrm{~N}$ coating. The arrows indicate the scratching direction.

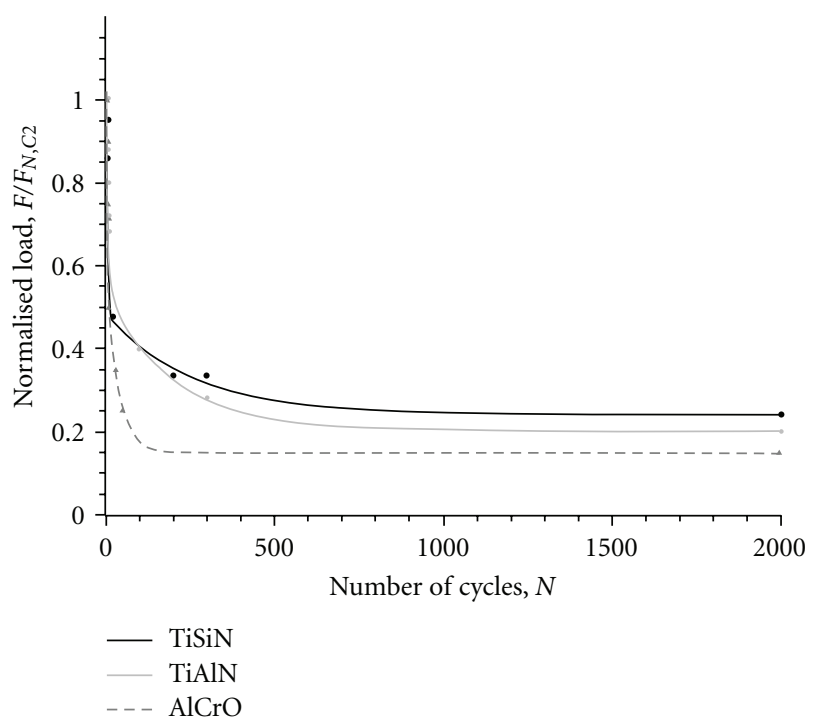

(a)

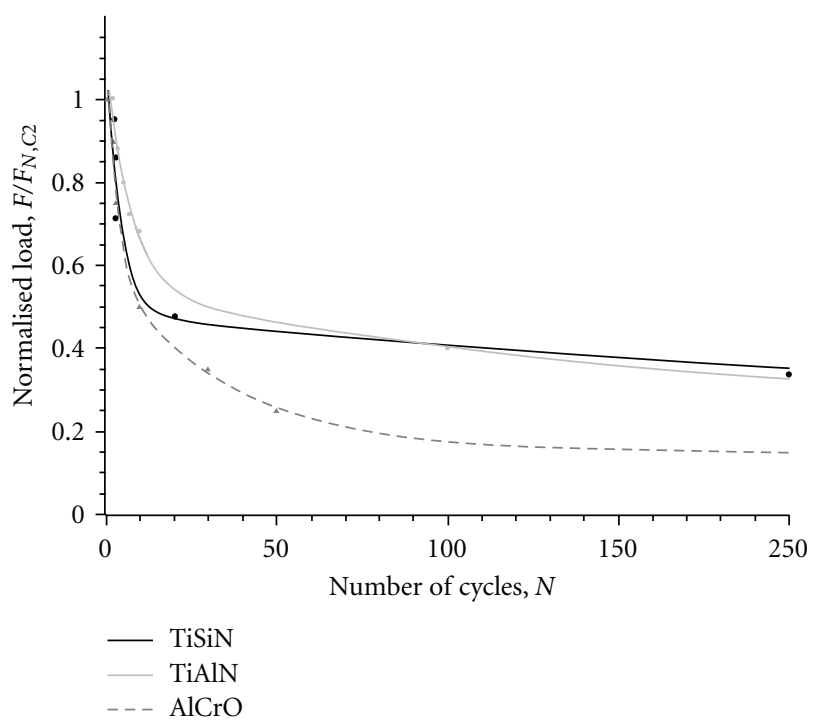

(b)

FIGURE 5: Normalised load-number of cycles curves for the coatings investigated showing the normalised normal load for continuous interfacial spalling. 


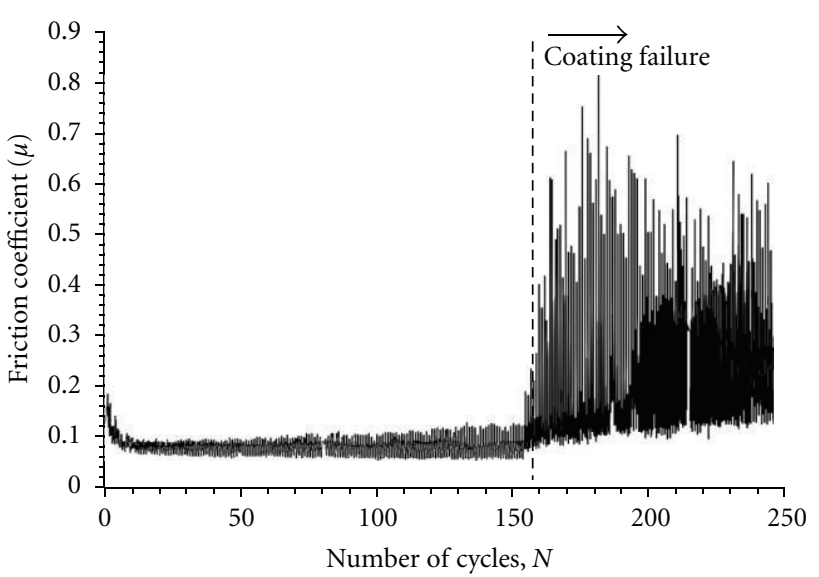

Figure 6: Friction coefficient-number of cycles curve for the $\mathrm{Ti}_{0.34}$ $\mathrm{Al}_{0.66} \mathrm{~N}$ coating illustrating the increase in friction when coating failure occurs.

3.2.2. Single Pass Scratch Test Behaviour. Table 3 shows the critical normal loads, $F_{N, C 1}$ and $F_{N, C 2}$, as obtained in the conventional single pass scratch test of the coatings investigated. As expected, the larger $200 \mu \mathrm{m}$ radius diamond stylus results in significantly higher critical normal loads. As can be seen, the $\mathrm{Ti}_{0.34} \mathrm{Al}_{0.66} \mathrm{~N}$ coating displays the highest critical normal loads and the $\left(\mathrm{Al}_{0.7} \mathrm{Cr}_{0.3}\right)_{2} \mathrm{O}_{3}$ coating the lowest critical normal loads. Also, the difference between the two critical normal load values, that is, $F_{N, C 1}$ and $F_{N, C 2}$, is for all coatings relatively small.

Examination of the scratch tested samples revealed that a number of coating failure and detachment mechanisms could be identified. Minor cracking and chipping of small, sub- $\mu \mathrm{m}$, coating fragments in connection to droplets and craters were sporadically observed already at very low normal loads $(\approx 1-2 \mathrm{~N})$ dependent on the size and type of defect. However, these failures were all very limited in size and restricted to the local defects. With increasing normal load the coating-substrate composites displayed the following major scratch induced damage mechanisms; plastic deformation and minor cracking (no coating material detached) within the scratch, chipping (cohesive failure) in combination with local interfacial spalling(adhesive failure) outside the scratch, and continuous interfacial spalling(adhesive failure) outside the scratch, see Figure 4 . The characteristics of the spalled off areas reveal that the observed adhesive failure is associated with the elastic recovery which occurs upon unloading behind the diamond stylus as it scratches the surface [30]. Consequently, plastic and elastic deformation of the cemented carbide substrate plays an important role for coating damage and as a result the tendency to chipping and spalling will decrease with decreasing normal load, that is, decreasing plastic deformation of the cemented carbide substrate. For normal loads above $F_{N, C 2}$, extensive plastic deformation within the scratch will occur resulting in coating fragments being pressed or squeezed into the cemented carbide substrate surface.

3.2.3. Multipass Scratch Test Behaviour. Figure 5 shows the results from the multi-pass scratch test where the influence of number of scratching cycles $(\mathrm{N})$ and load (normalised with respect to $F_{N, C 2}$ as obtained in the single pass scratch test) on the onset of continuous interfacial spalling along the circular wear track is presented. As can be seen, although minor differences exist, all coatings display a similar appearance with an increasing number of cycles to coating failure with decreasing normal load until a critical load, corresponding to a "fatigue limit", is reached below which no major coating failure such as chipping and spalling is obtained up to 2000 cycles. Further, it should be mentioned that the values of the critical loads are obtained by combining detailed characterisation of the scratch tracks with detection of changes in the acquired friction curves. An increase in friction, see Figure 6, indicates that coating failure occurs.

Examination of the circular wear tracks after different combinations of normal load and number of cycles shows that the major failure mechanisms observed in the conventional single pass scratch tests also are present in the multipass scratch tests, see Figures 7 and 8. Further, Figure 8(c) shows a crack obtained in the substrate/coating interface at the rim of the scratch. However, the multi-pass test also result in two new types of coating failure controlling the coating life time at a large number of cycles.

For normal loads below the "fatigue limit" gradual wear of the coating occurs. Two different wear mechanisms can be distinguished both acting on a sub- $\mu \mathrm{m}$ scale and typically after a large number of cycles. First, chipping of fine coating fragments is observed in connection to fatigue cracks obtained after a critical number of cycles, see Figure 9(a). Secondly, delamination of thin plate-like fragments, originating from a thin tribo film formed by compacting and sintering of sub- $\mu \mathrm{m}$ coating fragments at the diamond tip-coating interface, see Figure $9(\mathrm{~b})$, may also take place.

Consequently, for a combination of low loads, not resulting in pronounced deformation of the cemented carbide substrate, and large number of cycles the intrinsic tribological properties of the coating controls the life of the coating. It should be noted that the defects (droplets and craters) present in the coating do not necessarily result in any extensive coating wear at low normal loads. Also, the observed wear rate is relatively low; that is, the maximum reduction in coating thickness after 2000 cycles does not exceed $15 \%$ of the coating thickness for the coatings investigated.

For normal loads slightly above the fatigue limit large scale interfacial spalling resulting in complete exposure of the cemented carbide substrate within the scratch is observed after a large number of repeated contacts $(N>1000)$, see Figure 10. Consequently, fatigue controlled crack propagation at the coating-substrate interface has a significant influence on coating failure.

Figure 11 shows a coating failure map where the influence of normalised normal load and number of scratching cycles on the major damage mechanisms for the $\mathrm{Ti}_{0.34} \mathrm{Al}_{0.66} \mathrm{~N}$ coating is illustrated. In the map, the transition from a region (grey) corresponding to plastic deformation, minor cracking, and wear to a region corresponding to continuous interfacial spalling (dashed) is represented by a relatively 


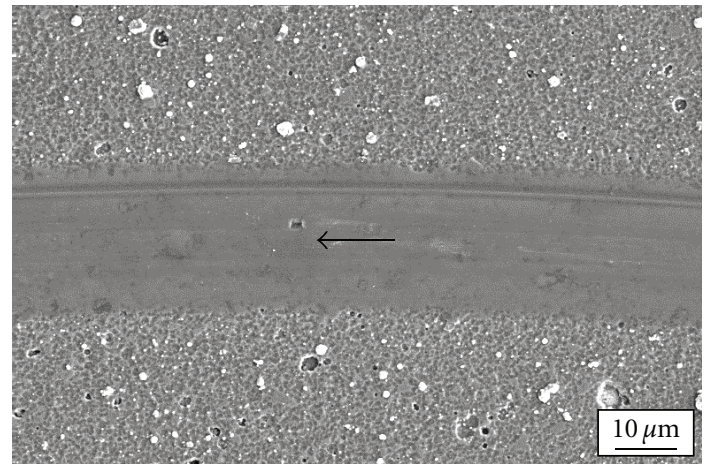

(a)

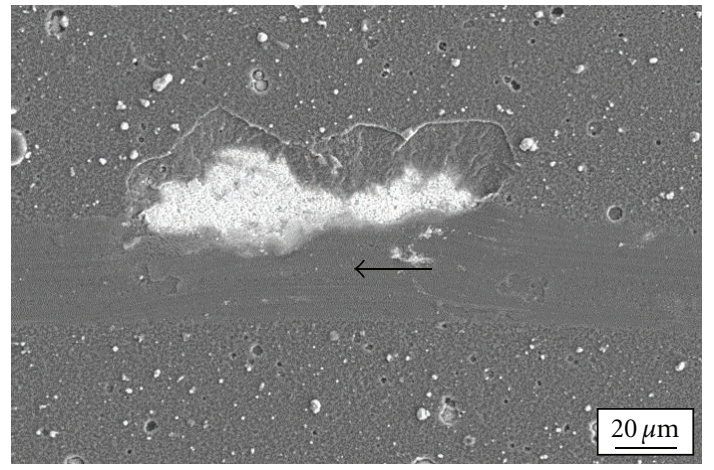

(b)

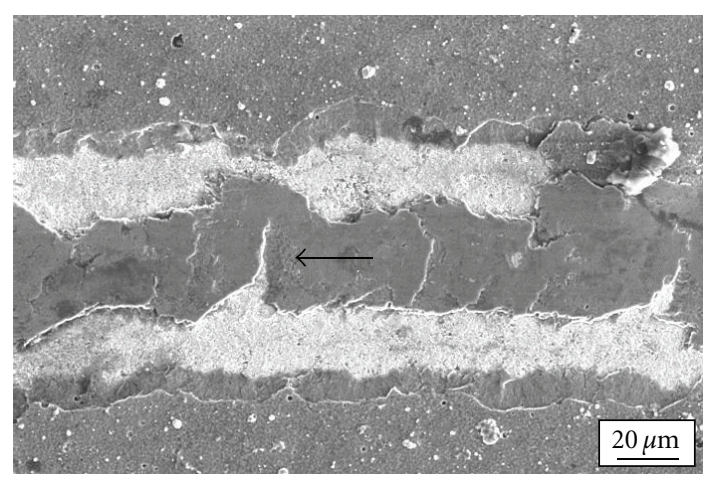

(c)

FIGURE 7: SEM micrographs illustrating the major coating failure mechanisms in the multi-pass scratch test. (a) Plastic deformation and minor cracking (no coating material detached), (b) chipping (cohesive failure) in combination with local interfacial spalling (adhesive failure), and (c) continuous interfacial spalling (adhesive failure) for $\mathrm{Ti}_{0.34} \mathrm{Al}_{0.66} \mathrm{~N}$ coating. The arrows indicate the scratching direction.

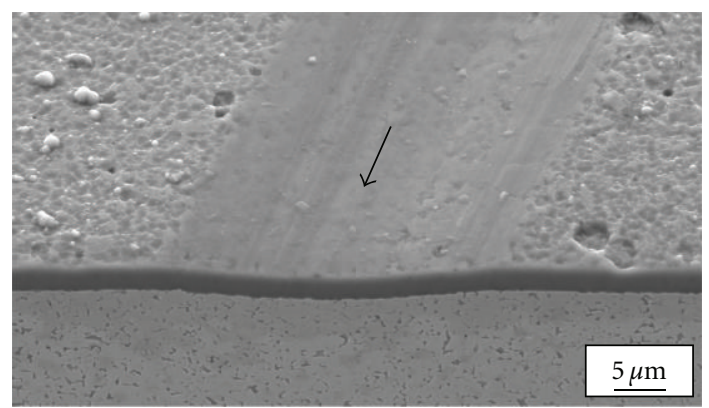

(a)

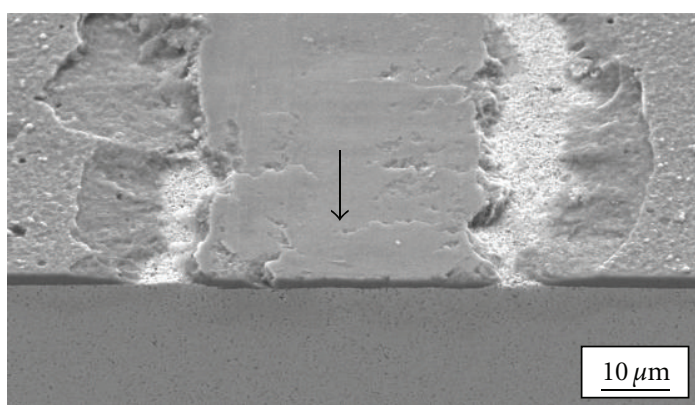

(b)

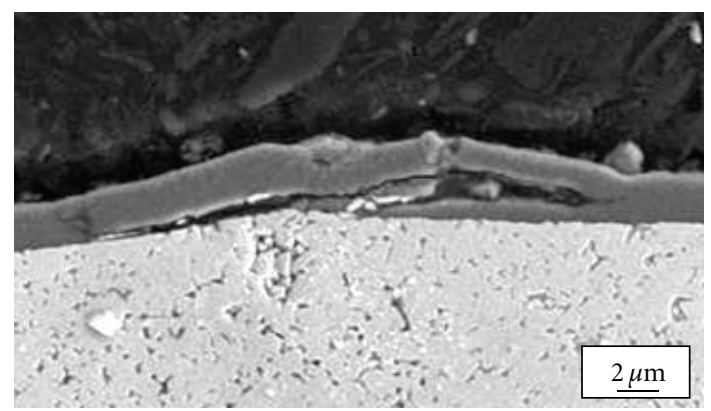

(c)

FIGURE 8: Cross-sections of the circular wear tracks illustrating (a) plastic deformation and minor cracking (no coating material detached), (b) continuous interfacial spalling (adhesive failure), and (c) interfacial cracking at the rim of a scratch track for $\mathrm{Ti}_{0.34} \mathrm{Al}_{0.66} \mathrm{~N}$ coating. The arrows indicate the scratching direction. 


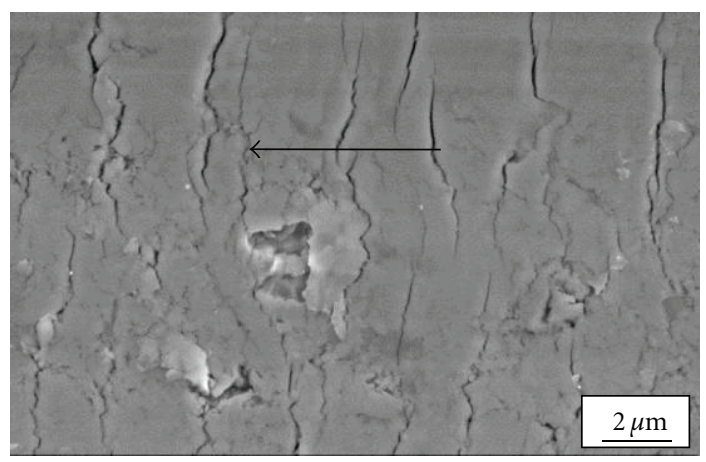

(a)

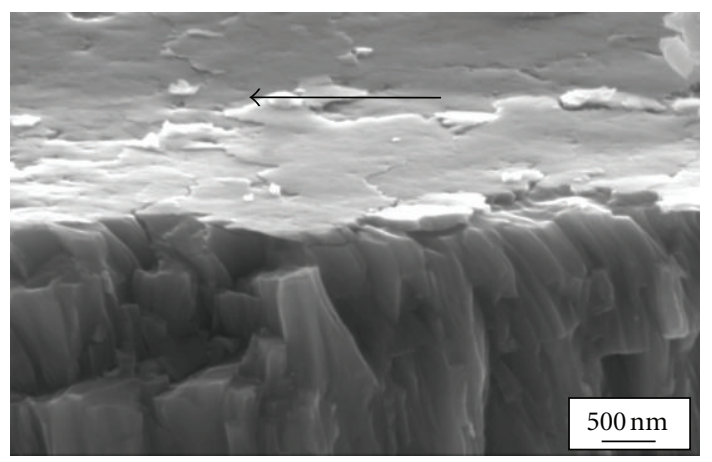

(b)

FIGURE 9: Wear mechanisms observed in the multi-pass scratch test. (a) Chipping of fine coating fragments in connection to transverse cracking and (b) delamination of thin plate-like fragments (fractured cross section) originating from a thin tribo film for $\mathrm{Ti}_{0.34} \mathrm{Al}_{0.66} \mathrm{~N}$ coating. The arrows indicate the scratching direction.

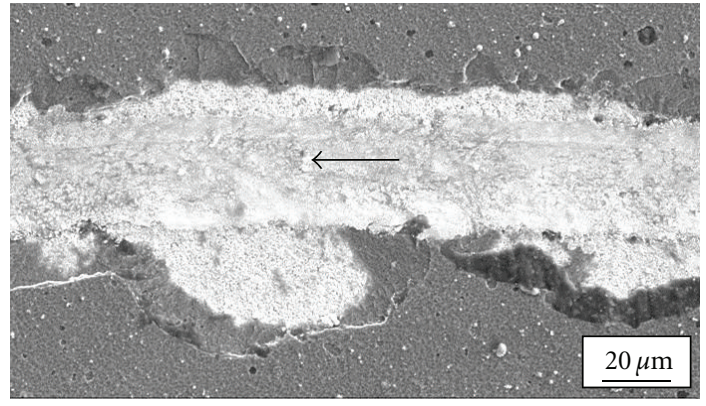

(a)

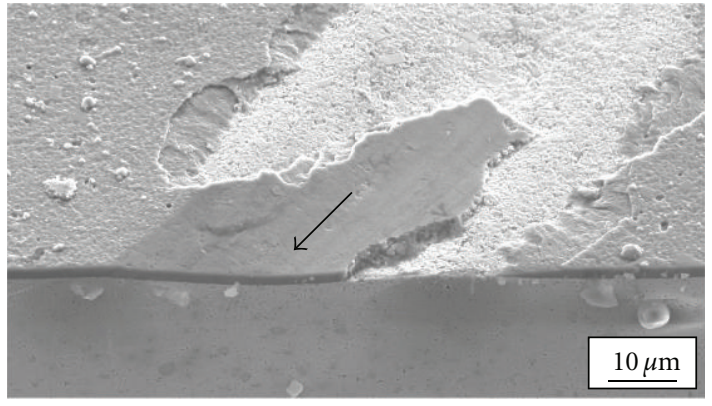

(b)

FIGURE 10: Complete exposure of the cemented carbide substrate due to continuous interfacial spalling (adhesive failure) within the circular wear track after a large number of repeated contacts $(N>1000)$ for $\operatorname{Ti}_{0.34} \mathrm{Al}_{0.66} \mathrm{~N}$ coating. The arrows indicate the scratching direction.

narrow band corresponding to chipping and local interfacial spalling. The narrow band signifies a quick transition from plastic deformation, minor cracking and wear via local interfacial spalling to continuous interfacial spalling with increasing normal load.

Region A $\left(F_{\text {norm }} \leq 0.15\right)$. For very low normalised normal loads the coating displays just a mild plastic deformation as revealed by the flattening of the as-deposited surface morphology in the scratch. With increasing normal load the plastic deformation extends through the coating into the substrate and with increasing number of cycles the coating starts to display fatigue induced cracking and mild wear caused by chipping or delamination of fine coating fragments.

Region B $\left(0.15 \leq F_{\text {norm }} \leq 0.25\right)$. For normalised normal loads below 0.20 complete interfacial spalling will occur at a high number of cycles $(N>1000)$. For normalised normal loads slightly above 0.20 coating damage by chipping and local interfacial spalling starts to occur at a critical number of cycles $(350<N<1000)$. Consequently, coating damage is affected by crack propagation within the coating and along the coating-substrate interface and high cycle fatigue controls the damage. With increasing normalised normal load, the critical number of cycles to chipping and spalling will rapidly decrease $\left(\mathrm{dN} / \mathrm{dF} \approx-1 \cdot 10^{3}\right)$ until a normalised normal load around 0.25 is reached where a transition to low cycle fatigue is obtained.

Region C. $\left(0.25 \leq F_{\text {norm }} \leq 0.60\right)$ : For normalised normal loads above 0.30 the critical number of cycles to chipping and spalling is relatively low, typically less than 250 350 . In this region the normal load is high enough causing extensive deformation of the cemented carbide substrate and the critical number of cycles to chipping and spalling is to a large extent controlled by the stress state and defect density at the coating-substrate interface promoting crack propagation during repeated cyclic loading.

Region D. Coating damage controlled chipping and interfacial spalling mainly due to elastic recovery caused by pronounced plastic deformation of the cemented carbide substrate during the scratching process. This failure occurs for normalised normal loads $F_{\text {norm }} \geq 0.60$ and is restricted to a low number of cycles, typically less than 10 . The decrease in number of cycles to local and interfacial spalling with increasing normal load is very low $(\mathrm{dN} / \mathrm{dF} \approx-1)$ in this region.

Further, retesting of the $\mathrm{Ti}_{0.34} \mathrm{Al}_{0.66} \mathrm{~N}$ coating after long term testing shows equal results as compared to former test, see Figure 12. The differences are most evident at higher 


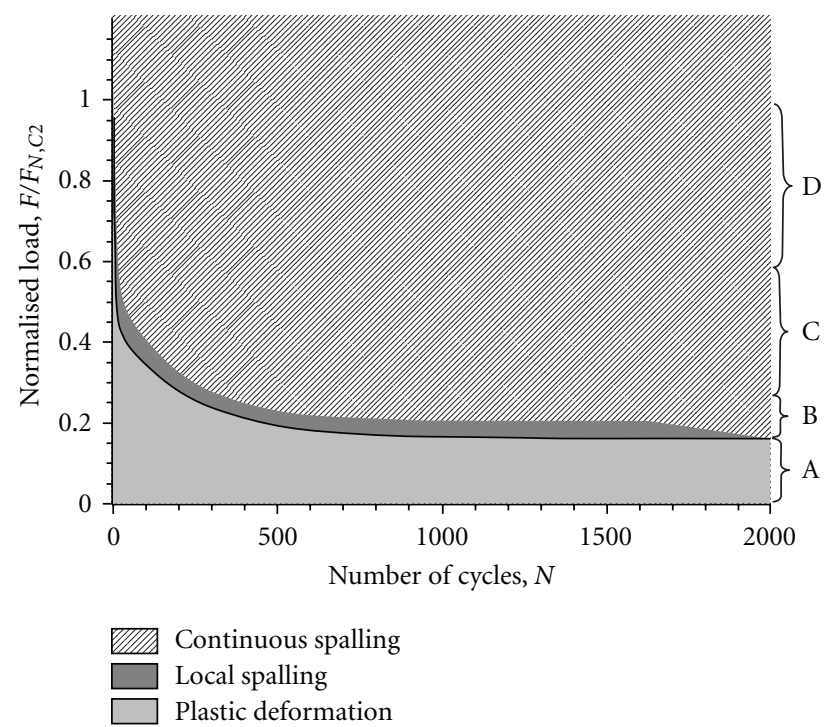

Figure 11: Coating failure map of the $\mathrm{Ti}_{0.34} \mathrm{Al}_{0.66} \mathrm{~N}$ coating as obtained from the circular multi-pass scratch test. The map illustrates the influence of normalized normal load and number of cycles on dominant failure modes, that is, plastic deformation, cracking and wear, local spalling, and continuous spalling. In the map, four different regions, A, B, C, and D, are indicated.

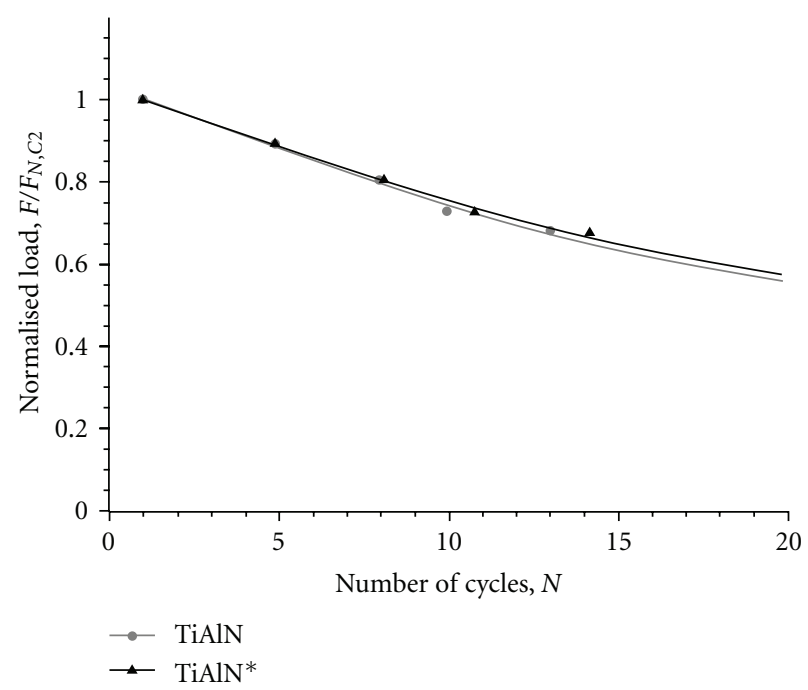

Figure 12: Normalised load-number of cycles curves for the $\mathrm{Ti}_{0.34} \mathrm{Al}_{0.66} \mathrm{~N}$ coating showing the normalised normal load for continuous interfacial spalling. The $*$ indicates retesting after long term testing of the other coatings investigated.

loads but are subtle which indicates that the technique is reproducible.

\section{Discussion}

4.1. Proposed Test Method. In the present study, circular multi-pass scratch testing using a pin-on-disc equipment is proposed as a test method to evaluate the fatigue, wear, chipping, and spalling behaviour of thin hard coatings under

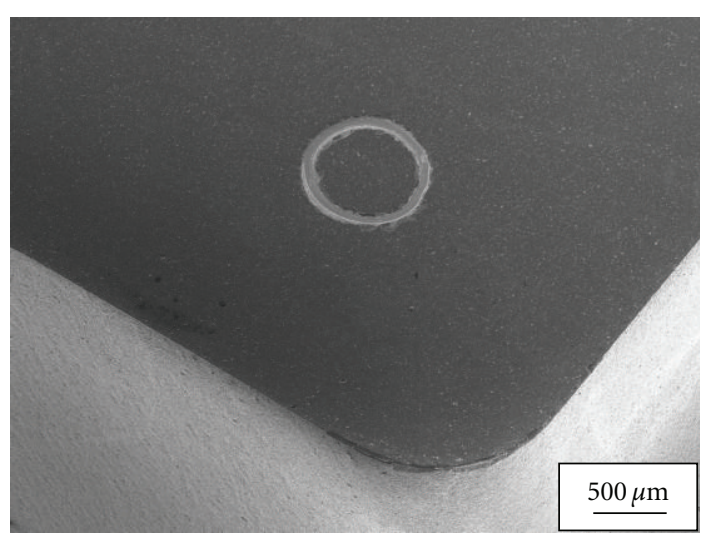

Figure 13: Circular wear track near the cutting edge of a coated cemented carbide insert illustrating the possibility to evaluate small test regions using the present test method.

repeated/cyclic sliding contact conditions. The results show that the test method is quick, simple and reproducible and can preferably be used to obtain relevant data concerning the mechanical and tribological properties of different coatingsubstrate composites. Other advantages of the proposed test method are.

(i) The test method utilizes a commercially available tribometer, an equipment widely used for tribological testing and present at many material laboratories.

(ii) The test method uses small, simple flat samples making it possible to easily evaluate for example, the effect of different types of pre- and post-coating deposition surface treatment processes, and so forth. Also, the small sample size facilitates post-test microscopy and surface analysis.

Besides, the use of a small diamond stylus as in the present study offers the possibility to characterise the coating at a very small, close to single asperity, scale. Also, the small size of the test region (the radius of the circular scratch track can be as small as $0.5 \mathrm{~mm}$ ) makes it possible to perform tests within small restricted areas. Consequently, the test method can be used as a virtually non-destructive test if the active region of the investigated sample is avoided. For example, it can be used to evaluate the cohesive and adhesive interfacial strength, fatigue, and wear resistance of coated cemented carbide inserts prior to cutting tests in order to correlate the obtained data to the tool life, see Figure 13.

Consequently, circular multi-pass scratch testing is a fast and powerful complement to conventional single pass scratch testing being one of the most common tests for the mechanical characterization of thin hard coatings. In combination with post-test scanning electron microscopy the proposed test method will give information about not only the critical normal loads and coating damage mechanisms at single pass scratch testing and a low number of loading cycles but also the fatigue and wear properties at a high number of loading cycles, $N>1000$. Compared with the common used impact tests used for evaluating the 
fatigue properties of thin hard coatings the proposed test is believed to more closely simulate the contact conditions and prevailing stress states in sliding contact tribosystems although the number of cycles are significantly lower than in the impact tests $[5,19-21]$.

It may be questioned whether the test approach, which comprises a large number of loading cycles, will result in extensive wear of the diamond stylus. Steinmann et al. found that unless the diamond tip shows extensive chipping due to "half-crown" shaped cracking the influence of diamond tip wear on the critical normal load is not significant [31]. However, as stated by the authors regular microscopic observations of the diamond tips are of utmost importance. Also, the use of high quality natural single-crystal diamond tips with the [100] direction oriented along the $z$-axis can substantially increase their life time. Furthermore, in order to optimize the life time the diamond stylus should be rotated $180^{\circ}$ before catastrophic damage is reached. Besides the above mechanical wear, the diamond tip may, depending on the contact conditions and the surrounding environment, suffer from tribo-oxidation and graphitization [32], which will influence on the wear resistance as well as the friction at the scratching (sliding) interface. Consequently, high scratching (sliding) speeds should preferably be avoided. In the present study, two high quality diamond styli with guaranteed spherical geometry were used and the wear/damage of these was restricted to mild polishing and initial "halfcrown" shaped cracking after completing the test series.

4.2. Coating Damage Mechanisms. When comparing the results from the conventional single pass scratch test with the circular multi-pass scratch test it can be concluded that both tests display similar major coating failure mechanisms as long as the normal loads in the multi-pass test is relatively high, typically $F_{\text {norm }} \geq 0.60$, and is restricted to a low number of cycles, typically less than 10 . Within this region coating failure is due to: plastic deformation and minor cracking (no coating material detached), chipping (cohesive failure) in combination with local interfacial spalling(adhesive failure), and continuous interfacial spalling(adhesive failure) outside the scratch. Also, the characteristics of the spalled off areas reveals that the adhesive failures in both tests are associated with the elastic recovery which occurs behind the diamond stylus as it scratches the surface [30]. However, while the conventional single pass scratch test mainly gives information of the mechanical response of the coatingsubstrate composite, the circular multi-pass scratch test also gives information of the tendency to surface fatigue and wear when exposed to a large number of contact cycles. Besides, it also makes it possible to determine a "fatigue limit" for the coating-substrate composite. In Table 4 and Figure 14 the observed mechanisms are illustrated by simplified schematic drawings and discussed in some detail.

The ranking of the coatings investigated is, keeping in mind that all coatings were deposited with identical interfacial properties, believed to be controlled by the differences in mechanical properties and defect density. Thus, the ranking with respect to spalling resistance obtained at low normal loads, that is, $\mathrm{Ti}_{0.86} \mathrm{Si}_{0.14} \mathrm{~N}>\mathrm{Ti}_{0.34} \mathrm{Al}_{0.66} \mathrm{~N}>\left(\mathrm{Al}_{0.7} \mathrm{Cr}_{0.3}\right)_{2} \mathrm{O}_{3}$, can be explained by the fact that the $\mathrm{Ti}_{0.86} \mathrm{Si}_{0.14} \mathrm{~N}$ coating displays the highest hardness and $\left(\mathrm{Al}_{0.7} \mathrm{Cr}_{0.3}\right)_{2} \mathrm{O}_{3}$ the lowest hardness, a high hardness reducing the tendency to plastic deformation of the substrate material and thus the stresses at the coating-substrate interface. Increasing normal load will increase the stresses at the interface and consequently the strength of the interface region will have an increased impact on the tendency to spalling. Thus the ranking displayed at normalized normal load above 0.5 , that is, $\mathrm{Ti}_{0.34} \mathrm{Al}_{0.66} \mathrm{~N}>$ $\mathrm{Ti}_{0.86} \mathrm{Si}_{0.14} \mathrm{~N}>\left(\mathrm{Al}_{0.7} \mathrm{Cr}_{0.3}\right)_{2} \mathrm{O}_{3}$, can be explained by the fact that the $\mathrm{Ti}_{0.34} \mathrm{Al}_{0.66} \mathrm{~N}$ displays the lowest defect density and $\left(\mathrm{Al}_{0.7} \mathrm{Cr}_{0.3}\right)_{2} \mathrm{O}_{3}$ displays the largest defect density of the coatings investigated, see Figure 5 and Table 2. At even higher normalized normal loads the tendency to plastic deformation of the cemented carbide substrate will increase and consequently have a strong impact on the tendency to spalling. As a result the different coatings will display similar spalling characteristics, see Figure 5.

\section{Conclusions}

In the present study a new test method based on multipass scratch testing is presented and used in order to evaluate the mechanical and tribological properties of arc evaporated coatings of $\mathrm{Ti}_{0.86} \mathrm{Si}_{0.14} \mathrm{~N}, \mathrm{Ti}_{0.34} \mathrm{Al}_{0.66} \mathrm{~N}$ and $\left(\mathrm{Al}_{0.7} \mathrm{Cr}_{0.3}\right)_{2} \mathrm{O}_{3}$ deposited on cemented carbide inserts. Based on the obtained results the following conclusions can be drawn.

(i) The multi-pass test method utilizes a commercially available pin-on-disc tribometer, an instrument widely used for evaluating the friction and sliding wear characteristics of materials, present in many tribology laboratories making the test easily accessible.

(ii) The multi-pass scratch test method is quick, simple, and reproducible and can preferably be used to obtain relevant information concerning the fatigue, wear, chipping, and spalling characteristics of different coating-substrate composites.

(iii) The simple and small sample size makes the test cheap and easy to combine with post-test microscopy and surface analysis. Also, the small size of the test region (the radius of the circular scratch track can be as small as $0.5 \mathrm{~mm}$ ) makes it possible to perform tests within small restricted areas; that is, the test can be regarded as a virtually non-destructive test.

(iv) As long as the wear/damage of the diamond tip is restricted to mild polishing and initial "half-crown" shaped cracking the effect on the scratching process and the resulting critical normal loads is negligible.

(v) Of the coatings investigated, the $\mathrm{Ti}_{0.34} \mathrm{Al}_{0.66} \mathrm{~N}$ coating displays the best performance under low cycle fatigue conditions while the harder $\mathrm{Ti}_{0.86} \mathrm{Si}_{0.14} \mathrm{~N}$ shows the best performance under high cycle fatigue conditions. 


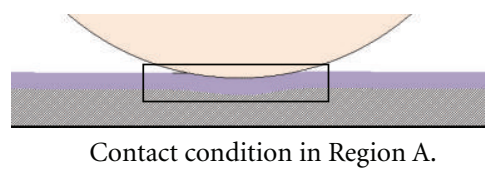

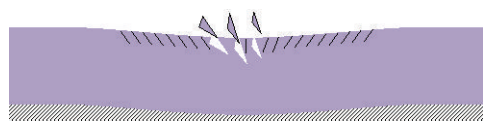

i) Chipping of fine coating fragments due to surface fatigue induced cracking.

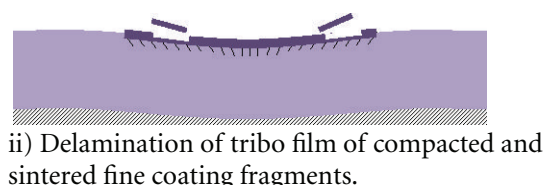

sintered fine coating fragments.

FIgURE 14: Wear mechanisms observed in Region A corresponding to normalised normal loads $<0.2$.

(vi) The intrinsic coating properties, including the defect density, have a significant impact on the fatigue properties of the coatings. Consequently, the presence of defects in the coating and the coating-substrate interface decreases the low cycle fatigue properties while the combination of coating defects and a low coating hardness decreases the high cycle fatigue.

\section{Acknowledgment}

The financial support for this work from the National Graduate School in Materials Science is gratefully acknowledged.

\section{References}

[1] P. A. Dearnley and E. M. Trent, "Wear mechanisms of coated carbide tools," Metals Technology, vol. 9, no. 2, pp. 60-75, 1982.

[2] P. A. Dearnley, "Rake and flank wear mechanisms of coated and uncoated cemented carbides," Journal of Engineering Materials and Technology, vol. 107, no. 1, pp. 68-82, 1985.

[3] Europeen Standard, Advanced technical ceramics-methods of test for ceramic coatings-Part: Determination of adhesion and other mechanical failure modes by scratch test, prEN1071-3:2000:E, CEN Management Centre, Brussels, Belgium, 42, 2000.

[4] J. L. Vossen, "Measurements of film-substrate bond strengths by laser spallation," in Adhesion Measurements of Thin Films, Thick Films and Bulk Coatings, K. L. Mittal, Ed., vol. 640 of ASTM Special Technical Publication, pp. 122-133, American Society for Testing Materials, Philadelphia, Pa, USA, 1978.

[5] O. Knotek, B. Bosserhoff, A. Schrey, T. Leyendecker, O. Lemmer, and S. Esser, "A new technique for testing the impact load of thin films: the coating impact test," Surface and Coatings Technology, vol. 54-55, pp. 102-107, 1992.

[6] M. Fallqvist, M. Olsson, and S. Ruppi, "Abrasive wear of multilayer $\kappa-\mathrm{Al}_{2} \mathrm{O}_{3}-\mathrm{Ti}(\mathrm{C}, \mathrm{N}) \mathrm{CVD}$ coatings on cemented carbide," Wear, vol. 263, no. 1-6, pp. 74-80, 2007.

[7] H. Czichos, S. Becker, and J. Lexow, "Multilaboratory tribotesting: results from the Versailles advanced materials and standards programme on wear test methods," Wear, vol. 114, no. 1, pp. 109-130, 1987.

[8] S. C. Lim and M. F. Ashby, "Wear-Mechanism maps," Acta Metallurgica, vol. 35, no. 1, pp. 1-24, 1987.

[9] D. Klafke, "Towards a tribological reference test-fretting test," in Proceedings of the 14th International Colloquium Tribology, pp. 1839-1846, Esslingen, Germany, January 2004.

[10] S. Baragetti, G. M. la Vecchia, and A. Terranova, "Variables affecting the fatigue resistance of PVD-coated components,"
International Journal of Fatigue, vol. 27, no. 10-12, pp. 15411550, 2005.

[11] F. Ledrappier, Y. Gachon, C. Langlade, and A. B. Vannes, "Surface fatigue behaviour mapping of PVD coatings for mechanical purposes," Tribotest, vol. 11, no. 4, pp. 333-343, 2005.

[12] K. Holmberg and A. Matthews, Coating Tribology: Properties, Mechanisms, Techniques and Applications in Surface Engineering, vol. 56 of Tribology and Interface Engineering, 2009.

[13] A.. Kassman, S. Jacobson, L. Erickson, P. Hedenqvist, and M. Olsson, "A new test method for the intrinsic abrasion resistance of thin coatings," Surface and Coatings Technology, vol. 50, no. 1, pp. 75-84, 1991.

[14] A. Matthews, "Methods for assessing coating adhesion," Le Vide, Les Couches Minces, pp. 7-15, October 1988.

[15] S. J. Bull, D. S. Rickerby, A. Matthews, A. Leyland, A. R. Pace, and J. Valli, "The use of scratch adhesion testing for the determination of interfacial adhesion: the importance of frictional drag," Surface and Coatings Technology, vol. 36, no. 1-2, pp. 503-517, 1988.

[16] P. J. Burnett and D. S. Rickerby, "The relationship between hardness and scratch adhession," Thin Solid Films, vol. 154, no. 1-2, pp. 403-416, 1987.

[17] M. T. Laugier, "An energy approach to the adhesion of coatings using the scratch test," Thin Solid Films, vol. 117, no. 4, pp. 243-249, 1984.

[18] S. J. Bull, "Failure modes in scratch adhesion testing," Surface and Coatings Technology, vol. 50, no. 1, pp. 25-32, 1991.

[19] K. D. Bouzakis and A. Siganos, "Fracture initiation mechanisms of thin hard coatings during the impact test," Surface and Coatings Technology, vol. 185, no. 2-3, pp. 150-159, 2004.

[20] K. D. Bouzakis, A. Asimakopoulos, N. Michailidis et al., "The inclined impact test, an efficient method to characterize coatings' cohesion and adhesion properties," Thin Solid Films, vol. 469-470, pp. 254-262, 2004.

[21] M. Stoiber, M. Panzenböck, C. Mitterer, and C. Lugmair, "Fatigue properties of Ti-based hard coatings deposited onto tool steels," Surface and Coatings Technology, vol. 142-144, pp. 117-124, 2001.

[22] S. Bennet, A. Matthews, J. Valli, A. J. Perry, S. J. Bull, and W. D. Sproul, "Multi-pass scratch testing at sub-critical loads," Tribologia, vol. 13, pp. 16-24, 1994.

[23] C. Liu, Q. Bi, and A. Matthews, "Tribological and electrochemical performance of PVD TiN coatings on the femoral head of Ti-6Al-4V artificial hip joints," Surface and Coatings Technology, vol. 163-164, pp. 597-604, 2003.

[24] J. Stallard, S. Poulat, and D. G. Teer, "The study of the adhesion of a TiN coating on steel and titanium alloy substrates using a multi-mode scratch tester," Tribology International, vol. 39, no. 2, pp. 159-166, 2006. 
[25] S. J. Bull and D. S. Rickerby, "Multi-pass scratch testing as a model for abrasive wear," Thin Solid Films, vol. 181, no. 1-2, pp. 545-553, 1989.

[26] M. G. Gee, "Low load multiple scratch tests of ceramics and hard metals," Wear, vol. 250, no. 1-12, pp. 264-281, 2001.

[27] M. Fallqvist and M. Olsson, "The influence of surface defects on the mechanical and tribological properties of VN-based arc-evaporatedcoatings," submitted to. Wear.

[28] L. M. Karlsson and L. M. Cruz-Orive, "The new stereological tools in metallography: estimation of pore size and number in aluminium," Journal of Microscopy, vol. 165, no. 3, pp. 391415, 1992.

[29] W. C. Oliver and G. M. Pharr, "An improved technique for determining hardness and elastic modulus using load and displacement sensing indentation experiments," Journal of Materials Research, vol. 7, no. 6, pp. 1564-1583, 1992.

[30] S. J. Bull, "Failure mode maps in the thin film scratch adhesion test," Tribology International, vol. 30, no. 7, pp. 491-498, 1997.

[31] P. A. Steinmann, Y. Tardy, and H. E. Hintermann, "Adhesion testing by the scratch test method: the influence of intrinsic and extrinsic parameters on the critical load," Thin Solid Films, vol. 154, no. 1-2, pp. 333-349, 1987.

[32] P. John, N. Polwart, C. E. Troupe, and J. I. B. Wilson, "The oxidation of (100) textured diamond," Diamond and Related Materials, vol. 11, no. 3-6, pp. 861-866, 2002. 

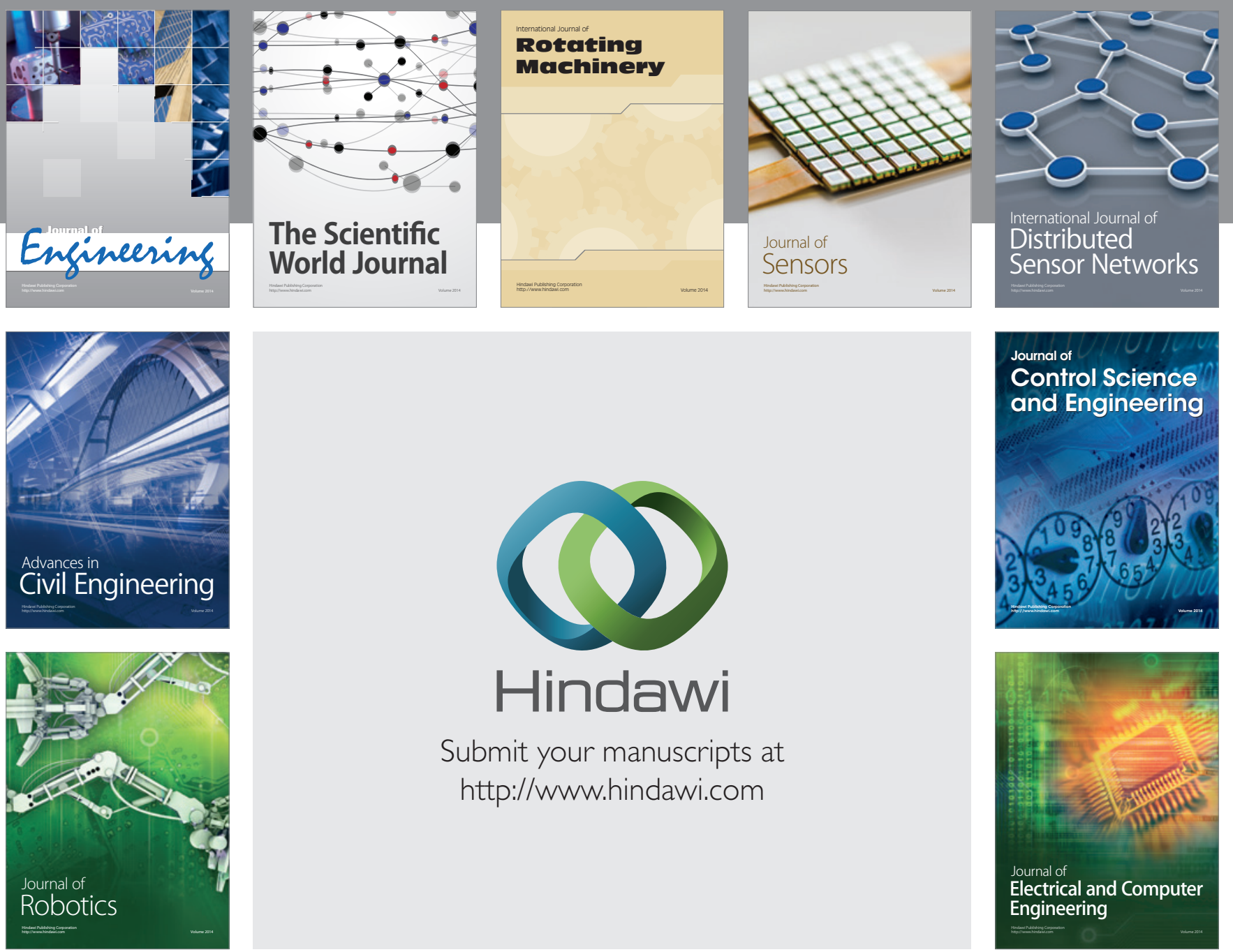

Submit your manuscripts at

http://www.hindawi.com
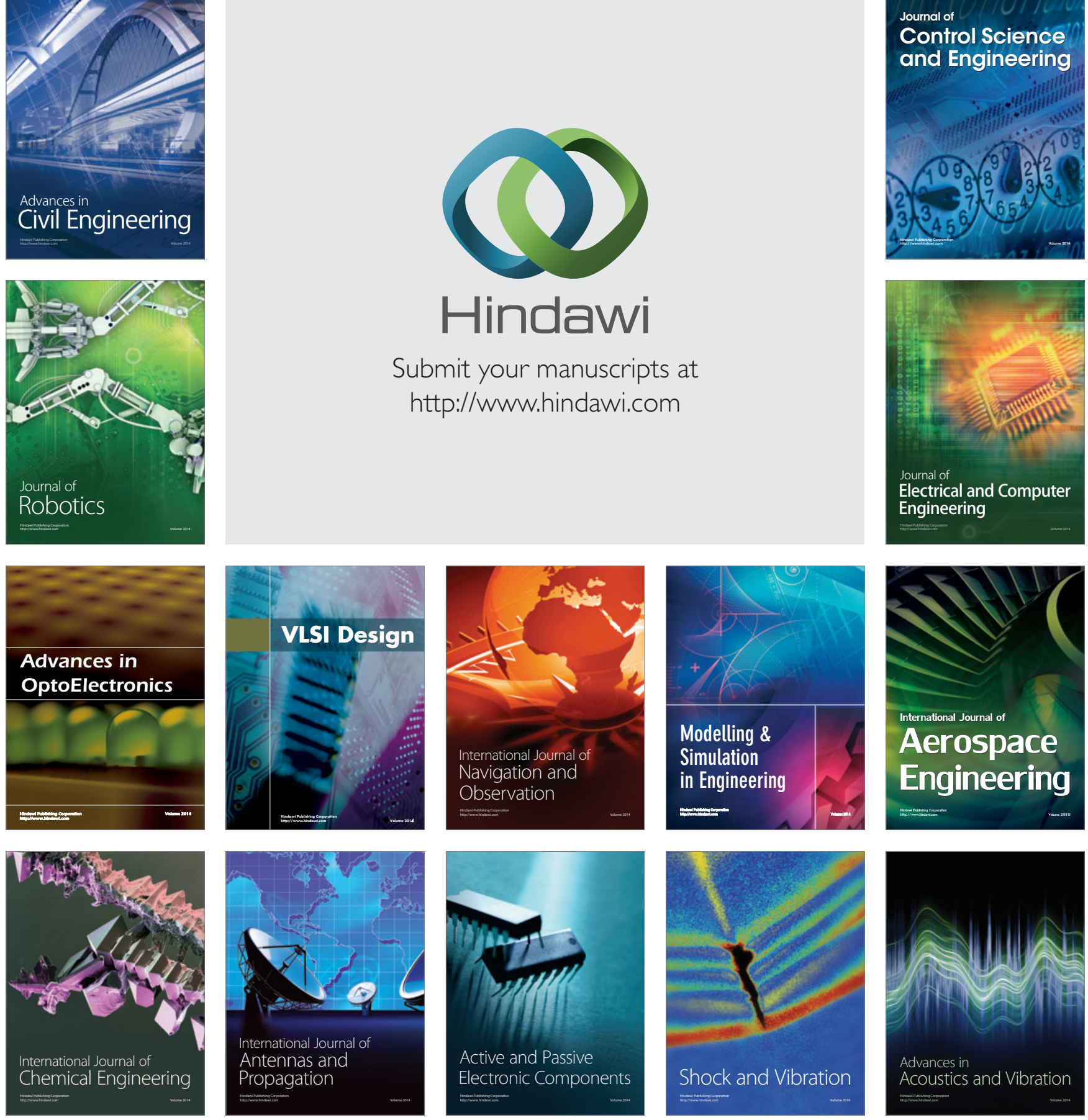